Review began 09/22/2021 Review ended 11/02/2021 Published 11/03/2021

๑) Copyright 2021

Gao et al. This is an open access article distributed under the terms of the Creative Commons Attribution License CC-BY 4.0. which permits unrestricted use, distribution, and reproduction in any medium, provided the original author and source are credited.

\section{Inadvertent Septal Ablation During Percutaneous Coronary Intervention}

\author{
Feng Gao ${ }^{1}$, Umair Khalid ${ }^{1,2}$ \\ Veterans Affairs Medical Center, Houston, USA \\ Corresponding author: Feng Gao, feng.gao@bcm.edu
}

1. Department of Medicine, Baylor College of Medicine, Houston, USA 2. Department of Medicine, Michael E. DeBakey

\begin{abstract}
We present a case of inadvertent occlusion of a septal artery from being jailed during percutaneous coronary intervention of left anterior descending artery. This resulted in partial loss of the interventricular septum. Risks of side branch occlusion and bifurcation stenting are discussed.
\end{abstract}

Categories: Cardiology

Keywords: side branch jailing, percutaneous coronary intervention complications, percutaneous coronary intervention, septal ablation, side branch occlusion

\section{Introduction}

Jailing of nonsignificant side branches during planned percutaneous coronary interventions (PCIs) is not an infrequent complication [1]. This occurs in situations where the proximity of a coronary lesion to an adjacent side branch results in a stent landing site that inevitability occludes the side branch ostium. Such occlusions are majority of the time clinically silent, structurally insignificant, and do not cause conduction defects [1]. Herein, we present a case of side branch occlusion during planned PCI that resulted in an inadvertent septal ablation.

\section{Case Presentation}

A 69-year-old man presented to the emergency room with two weeks of exertional dyspnea, unable to ambulate greater than 50 feet. Cardiopulmonary examination showed blood pressure of $131 / 82 \mathrm{mmHg}$, heart rate of 77 beats/min, a laterally displaced point of maximal impulse, bilateral dependent lung crackles, and bilateral lower extremity pitting edema. Medical history included uncontrolled hypertension, uncontrolled hyperlipidemia, peripheral artery disease, 50 pack-year smoking history, and alcohol use disorder. No history of recreational drug use was reported. Patient had no prior surgical history. The differential diagnosis for the etiology of clinical heart failure in this patient included ischemic cardiomyopathy, alcoholic cardiomyopathy, hypertensive heart disease, and heart failure with preserved ejection fraction.

On admission, a 12-lead electrocardiogram showed sinus rhythm with OS waves in leads V2-V4. Laboratory studies showed troponin I of $0.04 \mathrm{ng} / \mathrm{ml}$ and brain natriuretic peptide of $2498 \mathrm{pg} / \mathrm{ml}$. Transthoracic echocardiography (TTE) showed left ventricular ejection fraction of 30\%-35\% with moderate to severe global hypokinesis. Given patient's high likelihood of coronary artery disease, he underwent coronary angiography for workup of his cardiomyopathy, which revealed a diffusely diseased left anterior descending coronary artery (LAD) with worst stenosis up to 70\%-80\% (Figure $1 \mathrm{~A}-1 \mathrm{~F}$ ). 


\section{Cureus}
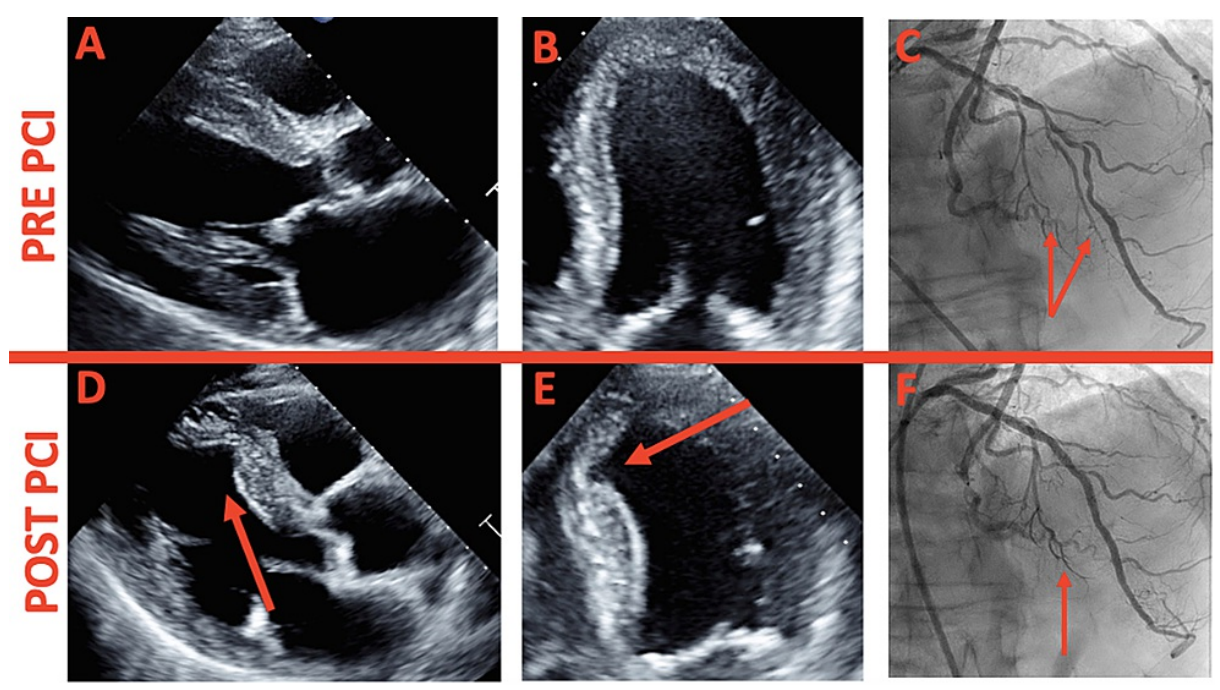

\section{FIGURE 1: Echocardiography and coronary angiography.}

(A) Pre-PCI TTE parasternal long view with normal septal thickness. (B) Pre-PCI TTE apical view with normal apical and septal wall thickness. (C) Pre-PCI with the diffuse LAD lesion on coronary angiography measuring 80 $\mathrm{mm}$ with ostial stenosis of midseptal branch and diagonal branch (red arrows: two midseptales). (D) Post-PCI TTE parasternal long view with new septal thinning, but no perforation (red arrow: septal defect). (E) Post-PCI TTE apical view with same septal thinning redemonstrated (red arrow: septal defect). (F) Post-PCI of LAD with loss of midseptal branch (red arrow: only one septal left).

PCI: percutaneous coronary intervention, TTE: transthoracic echocardiography, LAD: left anterior descending coronary artery.

Patient was deemed not a candidate for coronary bypass graft surgery (CABG) by cardiothoracic surgery; thus, PCI with intravascular ultrasound (IVUS) guidance was performed. The LAD lesion was crossed using a Choice PT wire (Boston Scientific, Marlborough, Massachusetts, USA) and predilated using multiple compliant balloons with good expansion. A $3.0 \times 28 \mathrm{~mm}$ drug-eluting stent (DES) was implanted in the distal LAD, $3.5 \times 38 \mathrm{~mm}$ DES in the mid-LAD, and $3.5 \times 28 \mathrm{~mm}$ DES in the proximal LAD with a very good final angiographic result (Figure $1 \mathrm{~F}$ ). The IVUS was used prior to stent implantation for lesion characterization and vessel sizing and post-stenting to confirm adequate stent expansion and apposition without any edge dissection. However, there was an occlusion of a septal perforating artery due to being jailed by the LAD stent struts (Figure $1 F$ ). We opted not to intervene on this septal branch to avoid disruption of LAD stent struts. Moreover, the patient did not have any clinical signs or symptoms from losing this septal branch. He did well and was subsequently discharged on appropriate medical therapy.

Six-month post-PCI, TTE showed improved left ventricular ejection fraction to $55 \%$, but thinning of the midanteroseptum and midinferoseptum was noted (Figure 1D-1E). No ventricular septal perforation was detected after evaluating the defect on multiple views with color Doppler.

\section{Discussion}

Side branch occlusion (SBO) may occur in $2 \%-10 \%$ of percutaneous coronary interventions with drugeluting stents, typically by mechanical straightening of the vessel and shifting of atherosclerotic plaque into side branch ostia [2-4]. Bifurcation stenting confers a higher risk of restenosis; hence, operators often chose provisional approach, especially if the side branch does not supply a large myocardial territory. However, bifurcation stenting is generally not performed for septal perforating arteries. Risk factors for SBO in our case included ostial septal artery stenosis, significant calcification of LAD, and placement of multiple overlapping stents [2].

This case was unique in that the SBO resulted in only partial loss of a septal wall. Such is similar to alcohol septal ablation for hypertrophic cardiomyopathy, although this generally involves ablating the first septal perforator resulting in loss of the basal septum at the left ventricular outflow tract [5]. Luckily the first septal perforator was not occluded in our patient, which would increase risk of complications including pacemaker implant for new heart block (9\%-20\%) and sustained ventricular arrhythmias (0.7\%-14\%) [6-8].

As seen in this case, $\mathrm{SBO}$ resulting from PCI did have significant septal infarction, even though there were no immediate clinical manifestations. However, if this patient has any LAD territory myocardial infarction (MI) in the future, there is at least a theoretical risk of ventricular septal defect (VSD) from further septal injury. Consequently, all PCI-related SBOs may not be clinically silent and we should take this into consideration prior to jailing any side branch during PCI. This is also one of the potential causes of post-PCI 
MIs, which we know are related to worse clinical outcomes in the future [9]. More data are needed to examine the clinical impact of PCI-related SBOs. For instance, there have been no studies that compared long-term adverse effects of septal side branch occlusions to occlusion of other side branches. Nonetheless, all prominent side branches should be protected by placing a coronary wire during PCI of main vessel $[10,11]$. This not only decreases the likelihood of SBO but also serves as a guide to reopen it if necessary.

\section{Conclusions}

Side branch occlusions related to PCI, particularly occlusion of large septal perforating arteries, may not be clinically silent. Risk of side branch occlusion should be taken into consideration when jailing a side branch during main vessel stenting. This risk is especially high in complex bifurcation lesions, presence of multiple layers of stents, and ostial side branch stenosis.

\section{Additional Information}

\section{Disclosures}

Human subjects: Consent was obtained or waived by all participants in this study. Conflicts of interest: In compliance with the ICMJE uniform disclosure form, all authors declare the following: Payment/services info: All authors have declared that no financial support was received from any organization for the submitted work. Financial relationships: All authors have declared that they have no financial relationships at present or within the previous three years with any organizations that might have an interest in the submitted work. Other relationships: All authors have declared that there are no other relationships or activities that could appear to have influenced the submitted work.

\section{References}

1. Arora RR, Raymond RE, Dimas AP, Bhadwar K, Simpfendorfer C: Side branch occlusion during coronary angioplasty: incidence, angiographic characteristics, and outcome. Cathet Cardiovasc Diagn. 1989, 18:210-2. 10.1002/ccd.1810180404

2. Popma JJ, Mauri L, O'Shaughnessy C, et al.: Frequency and clinical consequences associated with sidebranch occlusion during stent implantation using zotarolimus-eluting and paclitaxel-eluting coronary stents. Circ Cardiovasc Interv. 2009, 2:133-9. 10.1161/CIRCINTERVENTIONS.108.832048

3. Lansky AJ, Yaqub M, Hermiller JB, et al.: Side branch occlusion with everolimus-eluting and paclitaxeleluting stents: three-year results from the SPIRIT III randomised trial. EuroIntervention. 2010, 6 Suppl $\mathrm{J}: \mathrm{J} 44-52$.

4. Fischman DL, Savage MP, Leon MB, et al.: Fate of lesion-related side branches after coronary artery stenting. J Am Coll Cardiol. 1993, 22:1641-6. 10.1016/0735-1097(93)90589-s

5. Holmes DR Jr, Valeti US, Nishimura RA: Alcohol septal ablation for hypertrophic cardiomyopathy: indications and technique. Catheter Cardiovasc Interv. 2005, 66:375-89. 10.1002/ccd.20500

6. Sorajja P, Valeti U, Nishimura RA, et al.: Outcome of alcohol septal ablation for obstructive hypertrophic cardiomyopathy. Circulation. 2008, 118:131-9. 10.1161/CIRCULATIONAHA.107.738740

7. Fernandes VL, Nagueh SF, Wang W, Roberts R, Spencer WH 3rd: A prospective follow-up of alcohol septal ablation for symptomatic hypertrophic obstructive cardiomyopathy--the Baylor experience (1996-2002). Clin Cardiol. 2005, 28:124-30. 10.1002/clc.4960280305

8. van der Lee C, ten Cate FJ, Geleijnse ML, et al.: Percutaneous versus surgical treatment for patients with hypertrophic obstructive cardiomyopathy and enlarged anterior mitral valve leaflets. Circulation. 2005, 112:482-8. 10.1161/CIRCULATIONAHA.104.508309

9. Prasad A, Rihal CS, Lennon RJ, Singh M, Jaffe AS, Holmes DR Jr: Significance of periprocedural myonecrosis on outcomes after percutaneous coronary intervention: an analysis of preintervention and postintervention troponin T levels in 5487 patients. Circ Cardiovasc Interv. 2008, 1:10-9. 10.1161/CIRCINTERVENTIONS.108.765610

10. Burzotta F, Lassen JF, Lefèvre T, et al.: Percutaneous coronary intervention for bifurcation coronary lesions: the 15th consensus document from the European Bifurcation Club. EuroIntervention. 2021, 16:1307-17. 10.4244/EIJ-D-20-00169

11. Ford TJ, McCartney P, Corcoran D, et al.: Single- versus 2-stent strategies for coronary bifurcation lesions: a systematic review and meta-analysis of randomized trials with long-term follow-up. J Am Heart Assoc. 2018, 7 :e008730. 10.1161/JAHA.118.008730 